\title{
The stability of a reinforced concrete building frame: design by trial and adjustment
}

\author{
A. L. L. BAKER
}

Dr R. H. Wood, Deputy Chief Scientific Officer, Building Research Establishment, Associate Professor of Engineering and Science. University of Warwick

It is gratifying that the Paper indicates that multi-storey frame instability is being taken seriously even with reinforced concrete frames, for in 1962 a research committee of the Institution of Civil Engineers stated that, 'It is possible in reinforced concrete structures to avoid the type of instability observed by Wood in steel structures.' ${ }^{4}$ However, in the resulting discussion ${ }^{5}$ I showed that multiple plastic column hinges would give rise to the most drastic deterioration of stability then known. As a result Nahhas and $\mathrm{Yu}^{6}$ abandoned column hinges and also allowed only single hinges in beams (Fig. 7), their method being almost the same as Holmes and Gandhi's ${ }^{7}$ method for steel frames, both methods quite properly and successfully limiting the deterioration of stiffness. The Author's new proposals give the impression of being a simplified extension of Nahhas and Yu's findings, but in fact they are poles apart. To clarify this situation it is first necessary to criticize the Author's method, later indicating how a remaining use could be found for it.

36. The pattern of hinges shown in Fig. 7 is close to the maximum that can be tolerated in a frame, because the beam stiffness $K_{\mathrm{b}}$ has vanished at the right-hand end and has been reduced to $3 K_{\mathrm{b}} / 4$ at the left-hand end. With just a few extra central (or left-hand) beam hinges the frame will collapse. This is now well known. Less well known are the worse effects of extra column hinges. This can be shown with reference to the worked example quoted by Nahhas and $\mathrm{Yu}^{6}{ }^{6}$

37. If the collapse design load factor is unity, then the original elastic critical load factor for Nahhas and Yu's frame turns out to be about 4.32. With plastic hinges as shown in Fig. 7, the deteriorated critical load factor of what is still left elastic works out at 1.95. There is therefore limited positive stiffness left, and that is why the computer allowed only three extra column hinges (two in one storey) before collapse was imminent.

38. If extra hinges, top and bottom, were deliberately allowed in successive columns in each storey (Fig. 8(a), (b) and (c)) at something like half the number of permissible column hinges the critical load becomes less than the design load, and the Author's system has a critical load which has plunged to nearly a quarter of the design load. The consequences of this for practical desk designs are as follows.

39. At some stage in the design process the number of hinges will imply a critical load less than the design load $\left(\lambda_{\operatorname{det}}<1\right)$ and the whole frame will then have a negative stiffness. It is impractical for the desk design to continue because the appearance of each hinge must have been followed, one at a time-a task notoriously difficult even on computers.

40. The main objection is not, oddly enough, premature collapse, but that if any attempt is made to enforce stability by stiffening the columns then the chosen pattern of hinges will waste an enormous amount of concrete. In this example if $\lambda_{\text {det }}=0.29$ then $E I$ for all columns must be increased at least by a ratio $1 / 0 \cdot 29=3 \cdot 4$. Moreover the beams must also be increased in the same ratio, because critical loads are determined by beam/column stiffness ratios. This is the price of indiscriminate use of plastic hinges.

Paper published: Proc. Instn Civ. Engrs, Part 2, 1973, 55, Dec., 931-942. 


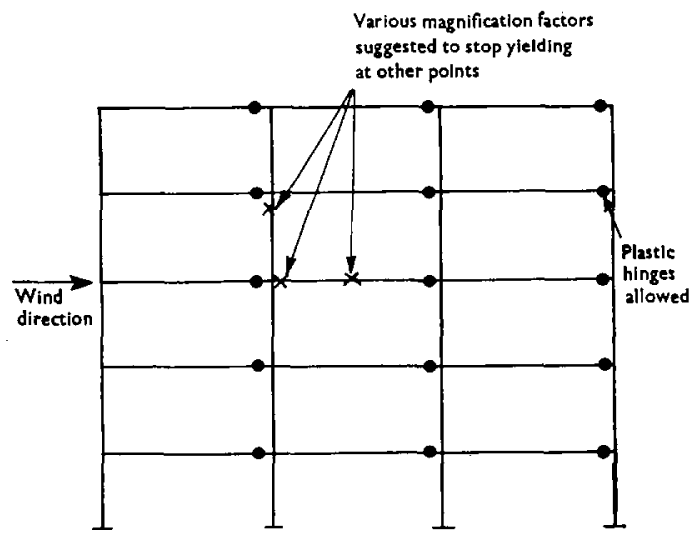

Fig. 7. Basis of Nahhas and Yu's and Holmes and Gandhi's method of frame design

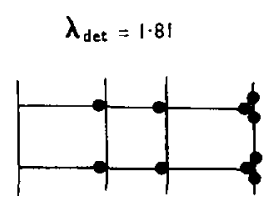

(a)

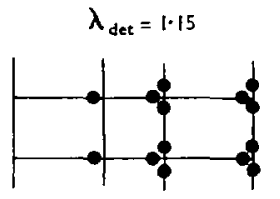

(b)

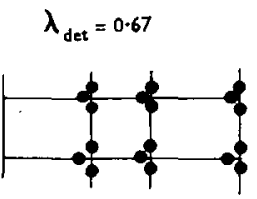

(c) $\lambda_{\text {det }}=0.29$

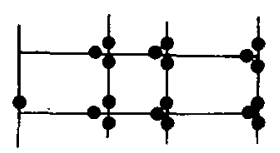

(d)

Statically determinate system (Baker)

Fig. 8. Deteriorated critical load factors with successive plastic hinges in columns (Nahhas and Yu's frame)

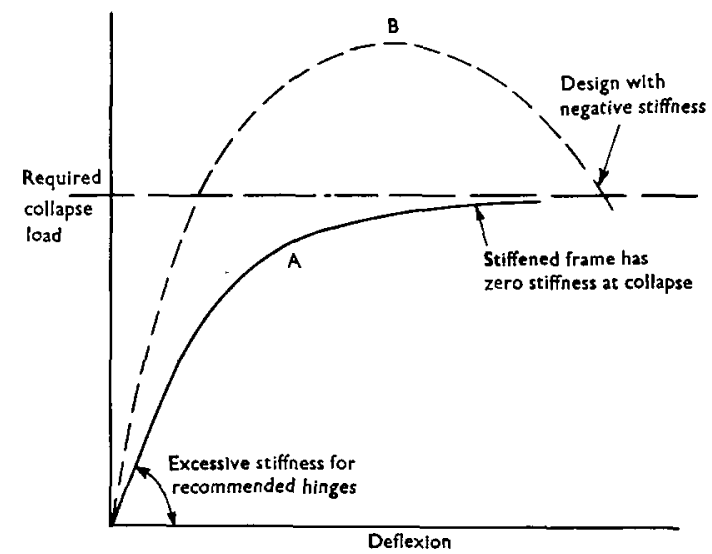

Fig. 9 
41. It is a mistake to argue that the descending branch of a load-deflexion curve implies a higher collapse load (Fig. 6) than the design load. The frame above, even stiffened some 3.4 times, would just have zero stiffness at the recommended hinge pattern (curve A, Fig. 9). A frame designed to have negative stiffness at the same required collapse load factor (curve B) would have to have a still more absurd stiffening in the elastic range.

42. The basic fallacy throughout is the assumption that equilibrium is ever a test for stability. It is vanishing stiffness which controls stability and which invalidates a lower bound approach using bending moment diagrams.

43. However, there is a remaining use for this kind of simplified approach, in much the same way as Heyman ${ }^{8}$ even used minimum weight plastic design as a start, afterwards making columns elastic. This is to use the Author's approach (ignoring instability) to give a reasonable starting size for members which will subsequently be modified according to Nahhas and Yu's treatment, or the Merchant-Rankine formula, which will be safe as long as multiple column hinges are avoided by making columns elastic.

\section{Professor Baker}

The frame, hinged as shown in Fig. 1, has by definition attained the ultimate limit state as a criterion of safe design. One more hinge due to a small increase of load will cause collapse.

45. The basis of the computer calculation ( $\$ 37$ and 38) is not stated. Reinforced concrete members, subjected to combined compression and bending, lose stiffness throughout the length between plastic hinges, because of inelastic effects. It is recommended that this should be allowed for by basing $E I$ values on an idealized momentrotation diagram assumed to be linear from zero load to a limit $L_{1}$, which is equivalent to a yield point defined by strain on the concrete or steel. The stiffness based on this yield condition at the section of maximum stress due to combined bending and axial load is assumed to apply throughout the length between plastic hinges. The local strains at plastic hinges are greater than the yield values at $L_{1}$ and generally depend on steel binding around the concrete. They concentrate over a short length, regardless of moment-curvature relations, and produce a hingeing action with nearly constant bending resistance up to a limit defined by strain. So $E I$ values between plastic hinges are based on a general deterioration of stiffness and, like the characteristics of the plastic hinges, are derived from extensive moment-rotation tests. The diagrams obtained from the tests indicate that bi-linear moment-rotation diagrams based on limiting strains of concrete and steel-with a perfectly plastic branch of limited length-are suitable idealizations to take account of inelastic deformations.

46. When hinges have formed, as shown in Fig. 2, verification of the compatibility of moment distribution and deformation establishes that the whole frame acts as a mechanism having constant resistance to sway, but is kept in equilibrium by the continuity of the beam and column in the end bay. Curve ADF of Fig. 6 can be explained as follows.

47. The bending moment in the continuous corner of the end bay increases continuously with $\lambda$ and at increasing rates as plastic hinges form at other sections and as $\boldsymbol{P}(\psi h+\delta)$ bending moments increase.

48. The unstable equilibrium position at $\mathrm{F}$ is at a reduced value of $\lambda$ because, although resistance moments are increasing until the last hinge forms, $P(\psi h+\delta)$ moments are increasing more rapidly, requiring a reduction in $\lambda$ for equilibrium. This could happen if members are slim. Hinges form under monotonically applied load in positions verified by the compatibility check because no hinge can form at mid-span of a beam until support hinges have formed, by design, and because no hinge can form at the continuous corner until hinges in all columns have formed since, 
by design, the corner resists the balance of anti-sway bending moments within the elastic range.

49. The distribution of axial loads influences column stiffness, but $E I$ values, based on the strains at the statically determinate state, should have the lowest values and be reasonably correct for relative stiffness values governing the distribution of resistance to sway.

50. The Paper recommends making design adjustments so that the rotations of column hinges are small and, in the windward columns at some levels, zero, where moments due to vertical and horizontal loads are opposed and nearly equal. If this is done, the required stiffness of the frame for the pattern of hinges which isolates each storey will probably not result in high extra cost and indeed may be desirable in a tall building.

51. Unstable equilibrium was assumed as a basis of design by Euler. In Fig. 6 the frame, having a diagram $A D F$, is in unstable equilibrium at $F$ but, before attaining this state, has been stable at $A$, the value of $\lambda$ at $A$ and $F$ being regarded as the ultimate limit state value.

52. To avoid hinges at the ultimate limit state in columns altogether is not necessarily optimum design. It saves reinforcement to transfer bending moments at supports to mid-span in continuous beams, but thereby increases the rotations of hinges at supports, which increases the sway of columns, which may be a disadvantage. Ideally, the rotation of column hinges should be kept very small for this reason, but it is an advantage to have column hinges in order to be able to establish, by design, compatibility of bending moment distribution and deformation. When the frame has thus become statically determinate at the ultimate limit state by the formation of sufficient hinges, the axial loads on the columns and their influence on stiffness can be found. Creep under combined bending and axial load-particularly if there are temperature effects-considerably influences the deformation of columns and safe limiting values of $E I$ must be adopted. Sway may thus, according to calculations, be increased and hinges so formed in columns, although a second order computer calculation, which ignores the effect of creep, may show otherwise. As the amount of sway appears to be sensitive to the hinge pattern and the latter can vary according to such indefinite quantities as creep rates, it may be wise to design for hinge patterns which make it possible to establish a simple, statically determinate system, in order to be able to study carefully the influence of $E I$ values and hinge rotations on sway, and hence on the ultimate strength of the frame.

\section{References}

4. Institution Research Committee. Ultimate load design of concrete structures. Proc. Instn Civ. Engrs, 1962, 21, Feb., 400-442.

5. Woon R. H. Discussion on Ultimate load design of concrete structures. Proc. Instn Civ. Engrs, 1962, 23, Oct., 253-255.

6. NahHas U. and YU C. W. The elastic-plastic design of reinforced concrete sway frames against instability. Proc. Instn Civ. Engrs, Part 2, 1972, 53, June, 41-56.

7. Holmes $M$. and GANDHI S. N. Ultimate load design for tall steel building frames allowing for instability. Proc. Instn Civ. Engrs, 1965, 30, Jan., 147-166.

8. Heyman J. An approach to the design of tall steel buildings. Proc. Instn Civ. Engrs, 1960, 17, Dec., 431-454. Discussion, 1962, 21, Apr., 832-851. 